\title{
Catálogo descriptivo de la lexicografía militar española anterior a la Primera Guerra Mundial ${ }^{*}$
}

\author{
FRANCISCO GAGO-JOVER \\ College of the Holy Cross
}

Aunque los últimos años han sido testigos de un renovado interés en los diccionarios de especialidad de los siglos XVIII y XIX — San Vicente (1995, 1996), Azorín Fernández (1998), Ahumada (2000), Battaner (2001), García Platero (2003), entre otros - aumentando día a día el número de investigaciones, todavía son muchos los diccionarios que quedan por estudiar. De todos ellos destacan los de terminología militar pues, a pesar del elevado número de diccionarios militares publicados desde comienzos del siglo XVIII hasta la Primera Guerra Mundial, apenas han sido estudiados por los especialistas, que desconocen en muchos casos su existencia. Las bibliografías de Serís (1964), San Vicente (1995 y 1996), Fabbri (1979 y 2002) y Niederehe (1994, 1999 y 2005) únicamente documentan la existencia de nueve obras — Sanz (1749), Castañón (1791-1792), Fernández Mancheño (1822), Sánchez Cisneros (1826), Marchesi (1849), J. D. W. M. (1863), Almirante (1869) y Rubió y Bellvé (1895-1901)un número sorprendente pues la Bibliografía militar de España de Almirante (1876), recoge un total de 12 obras editadas en los siglos XVIII y XIX, ocho de las cuales no aparecen recogidas en las bibliografías arriba citadas - Moretti (1828), Llave (1848), Corsini (1849), Enrile (1853), Agar y Aramburu (1853-1866), J. M. A. (1856), Hevia (1857), M. A. (antes de 1876).

Con el catálogo descriptivo que se ofrece en estas páginas se pretende, por lo tanto, no sólo determinar el número exacto de diccionarios, vocabularios y otras obras lexicográficas, tanto monolingües como bilingües, de temática militar publicadas antes de la Primera Guerra Mundial, sino también ofrecer una descripción lo más completa posible de sus contenidos. Antes, sin embargo, será preciso ofrecer unos breves comentarios sobre los límites cronológicos del catálogo, las obras consultadas para su elaboración y una descripción de la estructura de cada entrada del catálogo.

El límite cronológico inferior, 1749, está obviamente determinado por la primera obra recogida, ya que no se han encontrado obras lexicográficas de temática estrictamente militar anteriores a esta fecha. El límite superior obedece a razones de otra índole pues los avances tecnológicos experimentados durante la Primera Guerra Mundial

\footnotetext{
* Una primera versión de este catálogo, «Glosarios y diccionarios militares del siglo XIX», fue presentada en el Segundo Congreso Internacional de Lexicografía Hispánica, y posteriormente publicada en el volumen de actas (Gago Jover 2008).

FRANCISCO GAGO-JOVER, «Catálogo descriptivo de la lexicografía militar española anterior a la primera guerra mundial», Revista de Lexicografia, XVII (2011), pp. 33-63. ISSN: 1134-4539, e-ISSN: 2603-667. DOI: https://doi.org/10.17979/rlex.2011.17.0.3782
} 
suponen una transformación de la realidad material de la guerra y, por consiguiente, del vocabulario que la describe, quedando la mayoría de los términos definidos en las obras recogidas en este catálogo obsoletos a partir de 1918.

Para la elaboración del catálogo se consultaron, además de las bibliografías ya mencionadas, las listas de obras utilizadas que aparecen en los diccionarios de Moretti (1828), Tamarit (1853), Hevia (1857), Leguina (1912); y los repertorios bibliográficos de García de la Huerta (1760), Pasabón (1853), Hidalgo (1862-1881), Vidart (1871), Seco y Shelly (1877), Vidart (1888), Barado y Font (1890), Pezzi (1905), Palau (19481977), Geoghegan (1965), Hardin (1971) y Palfrey (1971). También fueron consultados una serie de bases de datos electrónicas: los catálogos de la Biblioteca Nacional, la Bibliothèque Nationale, la British Library y la Library of Congress, el Catálogo Colectivo del Patrimonio Bibliográfico Español, Google Books, el Catálogo Colectivo de la Red de Bibliotecas Universitarias (REBIUN) y WorldCat.

Las entradas del catálogo descriptivo están organizadas en orden cronológico y tienen la misma estructura cuatripartita: (a) descripción bibliográfica: autor, fecha, título, lugar de impresión, impresor, dimensiones, número de páginas; (b) contenidos/macroestructura: descripción de los contenidos y estructura general de la obra, número total de entradas; (c) microestructura: ${ }^{1}$ detallada caracterización de la organización de cada una de las entradas, el tratamiento de las unidades pluriverbales, el sistema de remisiones, etc.; (d) comentarios: diversas notas sobre aspectos concretos de cada obra - historia, localización, relación con otros diccionarios, etc.

\section{CATÁLOGO DESCRIPTIVO}

1. SANZ, Raimundo (1749): Diccionario militar, o recoleccion alphabetica de todos los terminos propios al arte de la guerra. Explicacion y practica de los trabajos que sirven al Ataque y Defensa de las Plazas: Sus ventajas y defectos según sus diferentes situaciones con un detalle Historico del origen y naturaleza de diferentes especies, tanto de Empleos antiguos y modernos como de las Armas que se han usado en diferentes tiempos de la Monarchia francesa hasta oy. Breve y extracta explicacion de la obligacion de los Oficiales de Infanteria Caballerìa Dragones Artillerìa è Ingenieros sea en Guarnicion ò Campaña segun el methodo presente de hacer la Guerra, Barcelona, Imprenta de Juan Piferrer; [15 cm; xx + 436 pp. +3 hh. plegadas]

Contenidos / Macroestructura: «Dedicatoria a D. Nicolás de Carvajal», pp. iii-iv; «Aprobación [Censura eclesiástica] del M. R. P. Fr. Francisco Galindo», pp. v-ix;

\footnotetext{
${ }^{1}$ Dada la incoherencia lexicográfica que todos estos diccionarios presentan en lo referido a la lematización — es decir, a la selección de la unidad léxica que encabeza la entrada lexicográfica y a la forma que esta unidad adopta (véase por ejemplo Porto Dapena, 2002: 174-178) — y de acuerdo con la práctica lexicográfica moderna, se ha evitado describir el lexema que encabeza la entrada del artículo como lema, empleando en su lugar la denominación de voz-guía.
} 
«Aprobación de D. Pedro Locuze», pp. x-xi; «Aprobación de D. Bernardo de Berart», pp. xii-xiii; «Cédula Real», pp. xiv-xv; «Fee de erratas», p. xiv; «Suma de la tasa», p. xvii; «Prólogo», pp. xviii-xix; «Diccionario militar», pp. 1-436 [629 entradas]. Las entradas, aunque están dispuestas según la letra inicial, no siguen un estricto orden alfabético - cuando la entrada en español comienza con la misma letra que la francesa, Sanz la mantiene bajo esa letra. Sin embargo, cuando la entrada en español comienza con letra diferente a la francesa, Sanz la sitúa bajo esta nueva letra, al comienzo de ella si todavía no ha llegado a esta sección en el texto francés, y al final si ya lo ha hecho. Los dígrafos $\mathrm{CH}$ y LL no tienen consideración de letras independientes. La sección correspondiente a la $\mathrm{V}$ contiene todas las entradas que comienzan con $\mathrm{U}$ y $\mathrm{V}$. Texto a una columna.

Microestructura: Las voces-guía que encabezan los artículos lexicográficos se marcan con letra versalita. Algunas entradas ofrecen una serie de voces-guía sinónimas o casi-sinónimas. Las remisiones se indican al final de la entrada mediante la fórmula Véase.

Comentarios: El Diccionario militar es traducción del Dictionnaire militaire, ou, Recueil alphabetique de tous les termes propres à l'art de la guerre de Aubert de la Chesnaye-Desbois (París, 1742), y quiere «hacer ver en Diccionario un extracto del modo antiguo, y moderno de hacer la Guerra» (xviii). El deseo del autor es «dar gusto a los que ya saben, y que sirva de enseñanza a los que empiezan a servir» (xix). La obra fue duramente criticada por Almirante y Vidart [Letras y armas] (es una traducción del francés, tan deplorablemente conforme con su original, que en sus páginas no se halla lo que significa tercio, ni maese de campo, ni pica; no se halla, en fin, ninguna de las palabras que tan famosas hicieron los triunfantes ejércitos españoles de Italia y de Flandes, 206) El Diccionario militar fue reeditado en 2007 (Gago Jover y Tejedo Herrero).

2. LUCUZE, Pedro (1755): Diccionario de fortificación en el que se explican sus términos para que pueda venir en conocimiento de sus partes cualquier oficial del ejército.

Comentarios: La información que tenemos sobre este diccionario proviene del propio Lucuze, quien en la introducción de sus Principios de fortificación (1772) nos da cuenta de la accidentada historia de este diccionario: «el Capitán General Marqués de la Mina [...] habiendo trabajado la grande obra de sus Reflexiones, sacadas por las experiencias de la Guerra pasada en Italia, Cerdeña, Nápoles, y Sicilia, me encargó escribiese un Diccionario de Fortificación para incluirle con ella [...] y con arreglo a estas circunstancias le formé el año 1755. Pero habiendo fallecido el General, sin que se haya dado providencia para la impresión de su obra, me ha parecido sacar a la luz mi diccionario» (ii-iii).

Almirante (1876: 455) ofrece la siguiente descripción del manuscrito: «148 hoj. $4^{\circ}$, del que hay muchas copias», aunque no señala en qué archivos o bibliotecas se conservan dichas copias. 
Capel (1983), repite la misma información ofrecida por Almirante, sin indicar tampoco el paradero de alguno de estos manuscritos. No ha podido localizarse ninguno de los manuscritos en los fondos bibliográficos de ninguna biblioteca o archivo.

3. LuCUZE, Pedro (1772): Principios de fortificación, que contienen las definiciones de los términos principales de las obras de la plaza y de campaña, con una idea de la conducta regularmente observada en el ataque, y defensa de las fortalezas. Dispuestos para la instrucción de la juventud militar, Barcelona, Thomás Piferrer; $[21 \mathrm{~cm}$; $32+318$ pp. +10 hh. plegadas]

Contenidos / Macroestructura: «Al lector», pp. i-xiii; «Cathalogo de algunos escritores militares españoles», pp. xiv-xxiv; «Indice de los puntos principales», pp. xxvxxxi; «Erratas», p. xxxii; «Introducción por la explicación de algunos términos de geometría», pp. 1-6; «Principios de fortificación. Sección primera: Términos de la fortificación real», pp. 7-93; «Principios de fortificación. Sección segunda: Términos de la fortificación de campaña», pp. 94-178; «Principios de fortificación. Sección tercera: Aplicación de las obras de campaña al ataque y defensa de las plazas», pp. 179-318. [aprox. 288 entradas]. Las entradas aparecen dispersas por el texto sin ningún tipo de ordenamiento alfabético.

Microestructura: Las voces-guía aparecen en cursiva, encabezando el párrafo o insertas dentro de él. En ocasiones se ofrecen voces-guía sinónimas o casi-sinónimas.

Comentarios: Lucuze refunde en estos Principios el diccionario redactado en 1755 , señalando en la introducción que «tal es este discurso, con la diferencia de haber mudado aquel título en el de Principios de Fortificación, aumentado de la regular conducta que se observa en el ataque, y defensa de las fortalezas» (iii). Las dos primeras secciones-《Términos de la fortificación real» $\mathrm{y}$ «Términos de la fortificación de campaña»-conformaban el núcleo del diccionario, pues son las únicas que contienen términos definidos. Sin embargo, al no poder consultar la versión manuscrita del diccionario, es difícil saber qué relación existe entre el diccionario de 1755 y los Principios de fortificación.

4. Ríos, Vicente de los (1770-1780): Diccionario militar para la traducción de Sepúlveda, manuscrito, Real Academia de la Historia Ms. 9/6285; [fols. 1-6 del manuscrito].

Contenidos / Macroestructura: Según López de Ayala y Conde Salazar (1994), editores del diccionario, la obra ocupa los seis primeros folios del legajo, que también contiene «una hoja suelta con notas referentes a la traducción del libro 27 de la Historia de Carlos $V$ y tres folios con foliación numerada con notas referentes a la traducción de la Historia de Carlos V» (33-34). El léxico está organizado en dos series de palabras: unas militares y otras reunidas bajo el epígrafe «voces marítimas», sin orden alfabético y en general con traducción. Para su edición reorganizan el diccionario en dos secciones. En la primera se recogen exclusivamente los sustantivos, adjetivos y adverbios, y se ordenan los términos alfabéticamente a partir del enunciado en nomina- 
tivo. [143 entradas]. En la segunda, aparecen los verbos y las expresiones verbales, ordenados alfabéticamente según la forma de infinitivo. [116 entradas].

Microestructura: Las voces-guía en latín, en letra negrita cursiva, aparecen ordenadas alfabéticamente a partir del nominativo o infinitivo. Las unidades pluriverbales se sitúan, en línea aparte, tras la entrada bajo la que se subordinan. Les sigue el equivalente (o equivalentes) en español. No se ofrece ningún otro tipo de información.

Comentarios: Vicente de los Ríos (Córdoba 1736-Madrid 1779), profesor de Artillería en el Colegio de Segovia y miembro de la Real Academia de la Historia, participa activamente en el proyecto académico de edición de las obras del humanista Juan Ginés de Sepúlveda, especialmente De rebus gestis Caroli $V$, de donde es extraído el material que conforma este diccionario.

5. CAStañón, Luis (1791-1792): Encyclopedia metódica. Arte militar, 2 vols, Madrid, Imprenta de Sancha; [31 cm; vol. 1 (A-CAZ): 563 pp.; vol. 2 (CE-GUA): 632 pp.]

Contenidos / Macroestructura: «Prólogo del traductor», pp. i-iii; «Correccione» [sic], p. iv; «Discurso preliminar por Mr. de Keralio», pp. v-xiv; «Diccionario», pp. 1563; 1-632 [538 entradas]. Texto a dos columnas.

Microestructura: Las voces-guía que encabezan los artículos lexicográficos se marcan con letra versal. Al final de algunas entradas figura, en paréntesis, la fuente que sirve de autoridad. Las voces-guía correspondientes a las diferentes acepciones y a las unidades pluriverbales siguen, en línea aparte, a la entrada bajo la que se subordinan, y van diferenciadas con letra versalita.

Comentarios: La Encyclopedia metódica. Arte militar, traducción incompleta del Art militaire de Keralio (París, 1784-1797) «se reduce a la parte de la Encyclopedia en que se hallan recopilados los mejores preceptos de los más célebres Autores del Arte Militar» (iii). Castañón, sin embargo, no se limita a la mera traducción e incluye 113 nuevas entradas -77 en la letra A, 30 en la B, y 6 en la $\mathrm{C}-$, y numerosas acepciones, «los artículos que principian con esta señal (N.) son nuevos; esto es, aumentados en la traducción» (iii), y añade material en el texto de algunas definiciones, «lo contenido entre dos estrellitas o asteriscos, adicciones del Traductor» (iii). La obra es, en esencia un compendio de doctrina militar, cuya disposición alfabética no parece al autor ni al traductor la «más a propósito para instruir» (iii).

Según se desprende de la lectura del «Prólogo del traductor», Castañón no llegó a conocer el Suplemento al Art militaire, «que tienen anunciado» (p. iii); desconozco los motivos que llevaron a Castañón a no traducir en su totalidad los tres primeros volúmenes de la obra francesa - $\mathrm{O}$, si lo hizo, el por qué nunca fue publicada la parte correspondiente a las letras $\mathrm{H}-\mathrm{Z}$. En la introducción a su Diccionario militar razonado, el anónimo autor, señala que la «traducción al Español se suspendió por ser poco conforme con nuestro sistema militar, y diferente en reglamento, ordenanzas, y en la composición de las distintas armas y cuerpos»». 
6. SANZ, Raimundo (1794): Diccionario militar, o recoleccion alphabetica de todos los términos propios al arte de la guerra. Explicacion y práctica de los trabajos que sirven al ataque y defensa de las Plazas, sus ventajas y defectos, segun sus diferentes situaciones con un detalle histórico del orígen y naturaleza de diferentes especies, tanto de empleos antiguos y modernos, como de las armas que se han usado en diferentes tiempos. Breve y extracta explicacion de la obligacion de los Oficiales de Infantería, Caballería, Dragones, Artillería é Ingenieros, sea en guarnicion ó campaña, segun el método presente de hacer la guerra, Madrid, Oficina de D. Gerónimo Ortega y herederos de Ibarra; [16 cm; $x+436$ pp.]

Contenidos / Macroestructura: «Lista de los señores subscriptores», pp. i-viii; «Prólogo al lector», p. ix; «Diccionario militar», pp. 1-436 [629 entradas]. Las entradas, aunque están dispuestas según la letra inicial, no siguen un estricto orden alfabético. Los dígrafos $\mathrm{CH}$ y LL no tienen consideración de letras independientes. La sección correspondiente a la $\mathrm{V}$ contiene todas las entradas que comienzan con $\mathrm{U}$ y $\mathrm{V}$. Texto a una columna.

Microestructura: Idéntica a la de la edición de 1749.

Comentarios: Con excepción del «Prólogo al lector» se elimina en esta segunda edición todo el material introductorio. Se corrigen también las erratas señaladas en la edición de 1749 y se moderniza la ortografía.

7. Willson, James (1794): A Pocket Vocabulary in Six Languages, viz. English, German, Dutch, French, Italian, and Spanish; containing such words, terms and questions, as are most generally in use, particularly in the military service, Londres, $\mathrm{R}$. Hidmarsh; [14 cm; iv + 100 pp.]

Contenidos / Macroestructura: «Dedication», pp. i-v; «Cardinal Numbers», pp. 2-4; «Ordinal Numbers», pp. 4-5; «Of Time», pp. 5-6; «Of the Days, Months, Seasons, \&c», pp. 6-9; «Of Fortification», pp. 9-18; «Military Utensils, Implements, \&c», pp. 18-19; «Names of Cannons, Arms, \&c», pp. 19-24; "Ammunition, and Things relating thereto», pp. 24-25; «Names of Officers, Troops, \&c», pp. 26-28; «Words of Command, Signals, Duty, \&c», pp. 29-35; «Forage and Provisions», pp. 36-41; «Wearing Apparel», pp. 41-42; «Furniture», pp. 43-45; «Substantives», pp. 45-49; «Employments», pp. 49-50; «Things for Clothing-Metals», pp. 50-51; «Weights and Measures», pp. 51; «Colours-Diversions, Plays, and Gaming», pp. 52-53; «The SensesCarriages», pp. 53; «Adjectives», pp. 54-56; «Verbs», pp. 56-71; «Interrogatories», pp. 72-76; «Tables of Coins», pp. 77-100. [745 entradas]. Texto paralelo en páginas enfrentadas a seis columnas, una por idioma.

Microestructura: Las voces-guía - tanto palabras sueltas como expresiones pluriverbales - se disponen en columnas paralelas, en páginas enfrentadas, en este orden: inglés, alemán, flamenco, francés, italiano y español. Los verbos en inglés se indican con (to) tras el infinitivo; no se incluye ninguna otra información.

Comentarios: En algunos de los catálogos consultados la obra aparece como impresa por J. S. Jordan en Londres, sin embargo la portada indica claramente que el impre- 
sor es R. Hindmarsh. En ocasiones, se señala como título de esta obra The soldier's friend, and traveller's vade mecum, que sin embargo no aparece en la portada de la edición. Las 745 entradas indicadas son aquellas plenamente relacionadas con la temática militar. La obra esencialmente es un diccionario de frases útiles organizado temáticamente en una serie de campos. La paginación del libro es irregular, las páginas 2 a 76 están numeradas en páginas enfrentadas (el verso y recto comparten el mismo número de página); las páginas 77 a 100 van numeradas normalmente. Hay numerosos errores ortográficos en las partes correspondiente al español y portugués: recamera, dismontar, contéra, forro. El autor indica en la dedicatoria que el propósito de su obra es «to facilitate the correspondence between armies composed of, and peasantry belonging to, many different nations; and give men reciprocal encouragement to look deeper into the language of those with whom they must communicate» (iii-iv).

8. Willson, James (1799): A New Pocket Vocabulary in Six Languages, viz. English, German, French, Italian, Spanish, and Portuguese; containing such words, terms and questions, as are most generally in use, particularly in the military service, Londres; [14 cm; iv + 100 pp.]

Comentarios: No ha podido localizarse ningún ejemplar de la edición de 1799 en ninguno de los catálogos o inventarios consultados, lo cual nos inclina a pensar que se podría tratar de una edición fantasma.

9. WILLSON, James (1809): The soldier's friend, and Traveller's Vade Mecum; or, A New Pocket Vocabulary in Six Languages, viz. English, German, French, Italian, Spanish, and Portuguese; containing such words, terms and questions, as are most generally in use, particularly in the military service, Londres, T. Egerton; [14 cm; 101 pp.]

Contenidos / Macroestructura: «Dedication», pp. i-iv; «Cardinal Numbers», pp. 24; «Ordinal Numbers», pp. 4-5; «Of Time», pp. 5-6; «Of the Days, Months, Seasons, \&c», pp. 6-9; «Of Fortification», pp. 9-18; «Military Utensils, Implements, \&c», pp. 18-19; «Names of Cannons, Arms, \&c», pp. 19-24; «Ammunition, and Things relating thereto», pp. 24-25; «Names of Officers, Troops, \&c», pp. 26-28; «Words of Command, Signals, Duty, \&c», pp. 29-35; «Forage and Provisions», pp. 36-41; «Wearing Apparel», pp. 41-42; «Furniture», pp. 43-45; «Substantives», pp. 45-49; «Employments», pp. 49-50; «Things for Clothing-Metals», pp. 50-51; «Weights and Measures», pp. 51; «Colours-Diversions, Plays, and Gaming», pp. 52-53; «The SensesCarriages», pp. 53; «Adjectives», pp. 54-56; «Verbs», pp. 56-71; «Interrogatories», pp. 72-76; «Tables of Coins», pp. 77-100; «Table Showing the Distances from Town to Town in German and English Miles», pp. 101. [745 entradas]. Texto paralelo en páginas enfrentadas a seis columnas, una por idioma.

Microestructura: Las voces-guía - tanto palabras sueltas como expresiones pluriverbales - se disponen en columnas paralelas, en páginas enfrentadas, en este orden: 
inglés, alemán, francés, italiano, español y portugués. Los verbos en inglés se indican con (to) tras el infinitivo; no se incluye ninguna otra información.

Comentarios: En ocasiones, se señala como título de esta obra The soldier's friend, and traveller's vade mecum, que sin embargo no aparece en la portada de la edición. La sección titulada «Table Showing the Distances from Town to Town in German and English Miles» en la página 101, no aparece en la edición de 1794. Tanto la microestructura como la macroestructura de la obra son idénticas a la de 1794. Aunque el número total de lenguas se mantiene constante (6), el portugués sustituye al flamenco. Las 745 entradas indicadas son aquellas plenamente relacionadas con la temática militar. La obra esencialmente es un diccionario de frases útiles organizado temáticamente en una serie de campos. La paginación del libro es irregular, las páginas 2 a 76 están numeradas en páginas enfrentadas (el verso y recto comparten el mismo número de página); las páginas 77 a 101 van numeradas normalmente. Hay numerosos errores ortográficos en las partes correspondiente al español y portugués: recamera, dismontar, contéra, forro. El autor indica en la dedicatoria que el propósito de su obra es «to facilitate the correspondence between armies composed of, and peasantry belonging to, many different nations; and give men reciprocal encouragement to look deeper into the language of those with whom they must communicate» (iii-iv).

10. FERNÁNDEZ MANCHEÑO, José (1822): Diccionario militar portátil o recopilación alfabética de todos los términos propios de las ciencias militares, explicación de los empleos de la milicia y sus obligaciones, y de las diferentes especies de tropas, clases distintas de armas antiguas y modernas, máquinas de guerra, \&c. \&c., Madrid, Imprenta de Miguel de Burgos; [18 cm; vii + 389 pp.]

Contenidos / Macroestructura: «Discurso preliminar», pp. iii-vii; «Explicación de las abreviaturas de esta obra», p. viii; «Diccionario», pp. 1-370 [2897 entradas]; «Adiciones», pp. 371-389 [90 entradas]. El dígrafo $\mathrm{CH}$ no tiene consideración de letra independiente. Texto a una columna.

Microestructura: Las voces-guía que encabezan los artículos lexicográficos se indican en letra en cursiva. En ocasiones se indica el campo de especialidad a que pertenece el término definido. Las voces-guía correspondientes a unidades pluriverbales siguen, en línea aparte, a la entrada principal, marcadas también con letra cursiva.

Comentarios: La obra es «un catálogo de voces propias del arte de la guerra, así científicas, como gubernativas y económicas; los significados de los empleos militares y sus respectivas obligaciones, diversas clases de tropa de que se compone el ejército español, diferentes armas ofensivas y defensivas que ha usado y usa, así como las máquinas de guerra de que se sirvieron los antiguos para los ataques de las plazas, y las que sirven en la actualidad; y una porción de otras ciencias, cuya utilidad no podrá menos conocer el observador curioso, y que aunque a primera vista no parezcan propias son de suma importancia, especialmente en tiempo de guerra» (v-vi) 
11. SÁnCHEZ CiSNERos, Juan (1826): Ensayo de un diccionario razonado sobre la ciencia de la guerra, Barcelona, Imprenta Viuda de A. Roca; [15 cm; x +200 pp.]

Contenidos / Macroestructura: «Al lector», pp. iii-x; «Diccionario», pp. 1-194; «Nota particular sobre el levantamiento de planos topográficos», pp. 195-200 [149 entradas]. Texto a una columna.

Microestructura: Las voces-guía se marcan con letra versal. Las unidades pluriverbales pueden aparecer ordenadas alfabéticamente o subordinadas a uno de los términos que la componen.

Comentarios: Más que un diccionario, la obra es un manual cuyo principal objetivo no es definir los términos sino proporcionar al general «muchos recursos, y aun dar ideas importantes y precisas para desempeñar su empleo cuando convenga» (vi). Las definiciones incluidas en esta obra son de carácter enciclopédico e incluyen ocasionalmente elementos propios de una definición lingüística.

12. MORETTI Y CASCONE, Federico (1828): Diccionario militar español-francés, Madrid, Imprenta Real; [22 cm; xl + $448+184+72$ pp.]

Contenidos / Macroestructura: «Carta al Rey», pp. iii-v; «Prólogo», pp. vii-xv; «Provisión y ordenanza de los Reyes Católicos (18-9-1495)», pp. xvi-xxi; «Noticia de las obras latinas, castellanas, italianas, francesas, inglesas y alemanas que se han consultado para la redacción de este Diccionario y su Apéndice», pp. xxii-xxxii; «Fee de erratas», pp. xxxiii-xxxix; «Explicación de las abreviaturas», p. xl; «Diccionario», pp. 1-400 [4709 entradas]; «Suplemento de algunas voces omitidas», pp. 401-448 [746 entradas]. Aunque el dígrafo $\mathrm{CH}$ no encabeza una sección propia, las palabras que comienzan con él aparecen al final de la $\mathrm{C}$. Texto a dos columnas.

Apéndice al Diccionario militar castellano francés. Contiene el manual alfabético razonado de las monedas, pesos y medidas de todos los tiempos y países, con sus reducciones a las equivalencias españolas y francesas, pp. 1-184.

Vocabulaire Français-Espagnol. pp. 1-72. «Avant-propos», p. 3; «Table des abréviations», p. 4; «Vocabulaire français-espagnol», p. 5-72 [5587 entradas]. Texto a dos columnas.

Microestructura: En el «Diccionario» las voces-guía correspondientes a unidades monoverbales se marcan con letra versal. Se indica la categoría gramatical, el campo de especialidad y el equivalente en francés. Las voces-guía correspondientes a unidades pluriverbales siguen, en línea aparte, a la entrada bajo la que se subordinan, y van diferenciadas con letra versalita.

En el «Vocabulaire» las voces-guía se marcan con letra redonda. Se indica la categoría gramatical. El equivalente o equivalentes en español del término francés aparecen en cursiva. Las unidades pluriverbales aparecen recogidas en el cuerpo de la entrada, precedidas por un guión.

Comentarios: Las definiciones se ciñen a «la ley severa de la correspondencia y definición de las voces, omitiendo su parte histórica y todo lo que sirve más bien de eru- 
dición que de enseñanza útil» (x). En la obra pueden hallarse «los términos técnicos antiguos del mismo modo que los modernos, fijando con precisión la diferencia que los tiempos o el uso han podido introducir» (xiv), incluyendo términos de «la esgrima y la equitación» (xi), «una concisa noticia histórica de las diferentes órdenes militares de caballería» (xii), y «algunas voces, que si bien no son técnicas, ni tienen una relación inmediata con las partes de que se compone el arte militar, servirán sin embargo para ilustrar aquellas, y formar ideas exactas de su verdadera aplicación» (xiii).

Con respecto a la presencia de equivalentes en francés de las voces en español y del Vocabulaire, se justifica su inclusión señalándose la ventaja de «poder aprender la correspondencia de las voces técnicas en una lengua tan útil y generalizada como la de la nación francesa, que tanto abunda en autores recomendables en todos los ramos del arte de la guerra» (ix). Aunque Moretti es consciente de que para que su obra fuese completa «se hacía preciso poner la correspondencia de las voces francesas al castellano, con sus definiciones en francés», el deseo de «economizar su costo, y reducir el Diccionario a un solo volúmen para su más fácil manejo» obliga al autor a limitar la segunda parte, el Vocabulaire, «a la simple correspondencia de las palabras del francés al español, omitiendo toda explicación y definiciones» pues el interesado en instruirse «no tiene más que buscar su correspondencia castellana, y guiado por ella encontrará en su respectivo lugar las definiciones o la explicación que desee en nuestra lengua» (xii).

13. EstébAnez CALDERÓn, Serafín (1844): «Voces y frases más necesarias para darse a entender en árabe», en Manual del oficial en Marruecos, ó Cuadro geográfico, estadístico, histórico, político y militar de aquel imperio, Madrid, Imprenta de D. Ignacio Boix; [21 cm; 342 pp.]

Contenidos / Macroestructura: «[Representación de los sonidos de la pronunciación árabe]», pp. 321-322; «Vocabulista árabe según el dialecto de Marruecos», pp. 322330; «[Algunas voces]», pp. 322-327; «Algunas partículas», p. 327; «Pronombres», pp. 327-328; «Algunas frases», pp. 328-330. No se diferencian tipográficamente los diferentes campos semánticos cubiertos en la sección «[Algunas voces]». [311 entradas]. Texto a una columna.

Microestructura: Las voces-guía - tanto palabras sueltas como expresiones pluriverbales - se disponen en columnas paralelas. Las palabras en árabe aparecen transliteradas al castellano según las convenciones establecidas al comienzo del capítulo. Para cada una de las frases en árabe se ofrece su traducción literal al castellano. No se incluye ninguna otra información.

Comentarios: Este vocabulario, que ocupa el capítulo 23 del Manual del oficial en Marruecos, es esencialmente un listado de palabras y frases útiles organizado temáticamente en una serie de campos, destacando por su interés militar los dedicados a la geografía básica, frutas y verduras, armas y oficiales, partes de la casa, animales, profesiones, partes del cuerpo y prendas de vestir. 
14. LlaVE, Pedro de la (1848): Vocabulario francés-español de términos de artillería, Segovia, Imprenta de Eduardo Baeza; [15 cm; 191, [1] pp.]

Contenidos / Macroestructura: «[Prólogo]», pp. 5-13; «[Nota]», p. 15; «Vocabulario francés-español de artillería», pp. 17-191 [2002 entradas]; «Correcciones», p. 193. Texto a una columna.

Microestructura: Las voces-guía se marcan con letra cursiva. El equivalente o equivalentes en español del término francés, y en ocasiones una breve definición, aparecen en redonda. Las acepciones y unidades pluriverbales siguen, en línea aparte, a la entrada principal.

Comentarios: El vocabulario da cabida «á todas aquellas voces de artilleria, fortificacion, puentes, minas, artes y oficios, que ordinariamente se encuentran en las obras facultativas de estos y los pasados tiempos» (12). Cuando el término definido no tiene equivalente en castellano el autor hace «una ligera explicación de la forma ú objeto de su significado para venir en conocimiento de él» (12).

15. CORSINI, Luis (1849): Vocabulario militar, que comprende las definiciones del arte de la guerra, y la tecnologia especial de las diversas armas que le constituyen, de la táctica peculiar á cada una, de la sublime, de la estratégia de la logística, y de la fortificación, castramentación y equitación. Para uso de los militares de todas armas, Madrid, Imprenta del Semanario e Ilustración a cargo de D. G. Alhambra; [15 cm; xvi $+17-572$ pp.]

Contenidos / Macroestructura: «Al Excmo. Señor D. Ramón María Narváez», pp. v-vii; «Advertencia», pp. ix-xvi; «Explicación de las abreviaturas», p. xvii; «Vocabulario militar», pp. 19-572 [3876 entradas]. Aunque el dígrafo $\mathrm{CH}$ no encabeza una sección propia, las palabras que comienzan con él aparecen al final de la $\mathrm{C}$. Texto a una columna.

Microestructura: Las voces-guía que encabezan los artículos lexicográficos se indican con letra versalita. Las unidades pluriverbales siguen, en línea aparte, a la entrada principal, marcadas también con letra versalita. Para facilitar la consulta, las denominaciones compuestas se alfabetizan «por la letra ó letras iniciales con que de cualquier modo principie aquella: así es que para hallar, por ejemplo, las de: medio baluarte, y de, doblar el fondo, no se las deberá buscar en las diversas acepciones de las palabras baluarte y fondo, sino en las de, medio y de, doblar» (xiv-xv).

Comentarios: El diccionario excluye «cuanto tiene relación con las armas desusadas, con los ejércitos de la antigüedad, y con los sistemas y organizaciones caducadas» (xi), suprimiéndose también «las voces militares cuya definición ha llegado a ser ociosa, por demasiado vulgar y conocida» (xi); sin embargo conserva voces que «aunque de uso anticuado, por considerarlas indispensables para la inteligencia más corriente y necesaria de la historia; y otras, bien que muy comunes, siempre que tienen acepciones diferentes, que convenía deslindar a fin de evitar el que se confundiesen; o cuando corresponden a especies genéricas o a cosas que se dividen en partes menos conocidas 
que la colectiva a que se refieren, y de las que es sin embargo importante y necesario para los militares el tener un exacto conocimiento» (xv).

16. MARTíneZ DEL Romero, Antonio (1849): «Glosario compuesto de varias palabras cuya esplicación es necesaria para la intelijencia del Catálogo», en Catálogo de la Real Armería, Madrid, Aguado; [22 cm; xx + $198+119$ pp. + x hh. de grabados].

Contenidos / Macroestructura: Catálogo de la Real Armería: «[Prólogo]», pp. iiixii; «Advertencia preliminar», pp. xiii-xvi; «Notas», pp. xvii-xviii; «Abreviaturas», p. xx; «Catálogo descriptivo, artístico e histórico de los objetos de la Armería Real de Madrid», pp. 1-198. El Glosario, paginado de forma independiente, sigue a: «[Advertencia]», p. 3; «[Glosario]», pp. 5-100 [327 entradas]. Texto a una columna. Siguen al Glosario varios apéndices: «Noticia histórica de los arcabuceros de Madrid», pp. 101109; «Noticia de varios espaderos famosos de Toledo», pp. 110-119; «Correcciones del catálogo», p. 120. Siguen, sin paginar, diez láminas con diversas marcas y contramarcas que aparecen en las armaduras, espadas, ballestas y armas de fuego custodiadas en la Real Armería.

Microestructura: Las voces-guía que encabezan los artículos lexicográficos se indican con letra versal negrita. En ocasiones se incluyen textos literarios o históricos para ilustrar el significado de la palabra que se define.

Comentarios: El glosario es una «nomenclatura, compuesta casi toda de términos de armería» (xv). «Muchos de los nombres de armas y armaduras, y de otros objetos poco comunes empleados en el Catálogo histórico anterior, no se incluyen en el siguiente Glosario, por hallarse bien definidos en el Diccionario de la lengua castellana redactado por la Real Academia» (3).

El Catálogo - y todos los suplementos en él insertos - ha sido frecuentemente atribuido a José María Marchesi, Director General de Reales Caballerías, Armería y Yeguada, y cuyo nombre es el único que figura en la portada del libro. Sin embargo, como el mismo Marchesi señala en el prólogo: "Al Sr. [Gaspar] Sensi se debe la colocación de los objetos, y al Sr. [Antonio] Martínez del Romero el Catálogo y Glosario que va a continuación; por mi parte no he tenido más mérito que haber pensado la reforma [de la Real Armería]» (xii).

17. IBÁÑEZ e IBÁÑEZ, Carlos y Juan Modet y Eguia (1853): Manual del Pontonero. Comprende todos los detalles de la instrucción del soldado, las maniobras de los trenes de reglamento, rodado y a lomo, y el servicio que desempeña el pontonero en campaña, Madrid, Imprenta del Memorial de Ingenieros; [22 cm; $3+\mathrm{ii}+381+\mathrm{xv}$ hh. de grabados].

Contenidos / Macroestructura: «Al lector»; «[Medidas y Abreviaturas]»; «Introducción», pp. i-iv; «Vocabulario del pontonero», pp. 1-55 [573 entradas], texto a una columna; «Capítulo primero: Cordelería», pp. 57-67; «Capítulo segundo: Descripción del material», pp. 68-79; «Capítulo tercero: Transporte del tren», pp. 80-115; Capítulo cuarto: Navegación», pp. 116-;160 «Capítulo quinto: Reconocimiento de los ríos», pp. 
161-172; «Capítulo sexto: Puentes normales», pp. 173-225; «Capítulo sétimo: Puentes anormales», pp. 226-;239 «Capítulo octavo: Comunicaciones secundarias», pp. 240253; «Capítulo noveno: Tren de puentes para la guerra de montaña», pp. 254-270; «Capítulo décimo: Puentes construidos con los recursos del país», pp. 271-332; «Capítulo undécimo: Medios que pueden emplearse para el paso de los ríos», pp. 333-355; «Capítulo duodécimo: Conservación de los puentes militares», pp. 356-364; «Capítulo décimo tercero: Destrucción y reparación de los puentes permanentes y provisionales», pp. 365-375; «Índice», pp. 377-379; «Erratas», p. 381.

Microestructura: Las voces-guía que encabezan los artículos lexicográficos se indican en letra en cursiva. Se indica la categoría gramatical. Se separan mediante || las acepciones. Las remisiones son muy poco frecuentes, y se indican con V.

Comentarios: El autor, capitán del cuerpo de ingenieros y oficial de pontoneros, indica que en el vocabulario «se definen las voces técnicas» con las que debe familiarizarse el pontonero pues así «se evita la confusión en las prevenciones y voces de mando, y quedan mejor determinados los trabajos que se quieren ejecutar» (ii).

18. ENRILE Y MÉNDEZ DE SOTOMAYOR, Joaquín María (1853): Vocabulario militar francés e inglés español, Paris, H. Vrayet de Surcy; [21 cm; [8], 274 pp.]

Contenidos / Macroestructura: «[Dedicatoria] Al Excmo. señor Don Francisco Javier Azpiroz», p. 5; «[Justificación del autor]», p. 5; «Obras consultadas al formar este vocabulario», p. 6; «Vocabulario francés-español», pp. 1-160 [4304 entradas]; «Vocabulario inglés-español», pp. 163-266 [4042 entradas]; «Apéndice francés-español», pp. 267-268 [35 entradas]; «[Apéndice] inglés-español», pp. 268-270 [62 entradas]; «Correcciones», pp. 271-274. Texto a una columna.

Microestructura: Las voces-guía no se diferencian tipográficamente del resto de la entrada. En ocasiones, los equivalentes españoles de los términos en francés o inglés van seguidos por una breve definición. Los infinitivos ingleses se indican con la preposición ‘to' entre paréntesis. Las remisiones son muy poco frecuentes.

Comentarios: Enrile, capitán de artillería, pretende con su vocabulario «hacer un servicio al cuerpo a que pertenece» (5). El Vocabulario francés-español de términos de artillería de Pedro de la Llave es la base de la sección francés-español, pues «mil novecientos están tomados de aquel» (6).

19. TAMARIT, Emilio de (1853): Vocabulario técnico del material de artilleria é ingenieros. Comprende una nomenclatura y definición de todas las máquinas y efectos del uso de ambos cuerpos; la de los instrumentos y herramientas de las artes y oficios que tienen relación con ella; verbos y voces genéricas correspondientes al armamento, pertrechos, construcciones y fortificacion, con la clasificación del membrete a que corresponde cada uno de los nombres en los inventarios de efectos de la cuenta y razón especial de Artillería, Madrid, Imprenta de la Biblioteca del Notariado, a cargo de J. G. Mancheño; [20 cm; xii + 248 pp.] 
Contenidos / Macroestructura: «[Dedicatoria] Al Excmo. Sr. D. Francisco de Mata y Alós, mariscal de campo», pp. iii-iv; «El Autor», pp. v-vii; «Diccionario», pp. 1-236; «Membretes que constituyen los inventarios de efectos del material de artillería con arreglo a ordenanza», pp. 239-241; «Fábricas del cuerpo de artillería en las que se usan herramientas, máquinas y efectos no comprendidos en los anteriores membretes», $\mathrm{p}$. 241; «Membretes que constituyen los inventarios de efectos del material de ingenieros, y su equivalencia con los de artillería», pp. 241-242; «Obras consultadas para la redacción del Vocabulario técnico del material de artillería e ingenieros», pp. 243-246; «Erratas», pp. 246-248. [2349 entradas]. Texto a una columna.

Microestructura: Las voces-guía se marcan con letra versal. Las acepciones y las unidades pluriverbales, diferenciadas también con letra versalita, siguen, en línea aparte, a la entrada bajo la que se subordinan. Los números al final de cada entrada remiten a la última sección del diccionario (pp. 239-242) y sirven para determinar la categoría a la que pertenece cada efecto.

Comentarios: Según el propio subtítulo, el diccionario «comprende la nomenclatura y definición de todas las máquinas y efectos del uso de ambos cuerpos [artillería e ingenieros]; la de los instrumentos y herramientas de las artes y oficios que tienen relación con ella; verbos y voces genéricas correspondientes al armamento, pertrechos, construcciones y fortificación».

20. AGAR, Luis de (1853-1866): Diccionario ilustrado de los pertrechos de guerra, [ilustraciones de Joaquín Aramburu], Madrid, Lit. Tormentaria de C. Echauri; [32 cm; 456 pp. Edición litográfica. Publicado en 38 entregas entre los años 1853 y 1866]

Contenidos / Macroestructura: «[Diccionario]», pp. 1-456 [1630 entradas]. El dígrafo $\mathrm{CH}$ no tiene consideración de letra independiente. Texto a una columna.

Microestructura: Las voces-guía, tanto de unidades monoverbales como pluriverbales, se marcan en la mayoría de los casos con letra versal negrita. La voz-guía aparece en letra gótica negrita cuando corresponde a una entrada que encabeza una serie de subentradas, estas últimas aparecen en letra versal negrita, en línea aparte - a partir de la letra LL, correspondiente a la entrega 23, esta distinción no siempre se observa; véanse, por ejemplo, las entradas de mazo, nivel, pólvora, sonda, tornillo, entre otras. Equivalente francés de la palabra o expresión definida. La mayoría de las entradas van acompañadas de ilustraciones.

Comentarios: El diccionario incluye términos pertenecientes, directa o indirectamente, al material de artillería: piezas, afustes, explosivos, herramientas, medios de transporte, etc. La afirmación de Hevia de que «esta obra quedó incompleta, pues solo han salido 21 entregas» (viii) es incorrecta, ya que, tras el paréntesis de unos años, se reanudó su publicación. El diccionario se reeditó en edición facsímil en 1975, Madrid, Asociación El Cid. Museo del Ejército.

21. ANÓNIMO (1854): Diccionario de equitación para el uso de los oficiales del arma de Caballería, Madrid, Imprenta de M. Rivadeneyra; [15 cm; 226 pp.] 
Contenidos / Macroestructura: «[Prólogo]», p. 5; «Diccionario», pp. 7-226 [1415 entradas]. Texto a una columna.

Microestructura: Las voces-guía que encabezan los artículos lexicográficos, tanto las correspondientes a las unidades monoverbales como a las pluriverbales, se marcan con letra versalita. Las remisiones se indican al final de la entrada mediante la fórmula Véase.

Comentarios: Este diccionario, aprobado como obra de texto por real orden de 22 de junio de 1854, contiene «todas las voces técnicas que mas se usan en el picadero; como tambien una extensa explicacion acerca del sistema que haya de seguirse para la doma, enseñanza y manejo de los caballos, según reglas del arte de equitacion» (5).

22. MARTíneZ DEL Romero, Antonio (1854): «Glosario compuesto de varias palabras cuya esplicación es necesaria para la intelijencia del Catálogo», en Catálogo de la Real Armería, $2^{\mathrm{a}}$ ed., Madrid, Aguado; $22 \mathrm{~cm}$; xx $+198+119$ pp. $+\mathrm{x}$ hh. de grabados].

Contenidos / Macroestructura: Idéntica a la edición de 1849.

Microestructura: Idéntica a la edición de 1849.

Comentarios: En esta reimpresión del Catálogo, figuran en la portada los nombres de Joaquín Fernández de Córdoba y Gabriel Campuzano y Herrera, sin embargo, como ya se indicó en los comentarios a la edición de 1849 de este mismo Catálogo, el autor del glosario es Antonio Martínez del Romero.

23. J. M. A. Diccionario militar, ayuda memoria del Oficial de Caballería en campaña. Resúmen alfabético, etc.

Comentarios: Según Almirante (1876: 794) esta obra, anunciada en la Revista Militar de octubre 1856, nunca llegó a ser impresa. No se encuentra referencia a esta obra en ninguna otra fuente bibliográfica.

24. HEVIA, Deogracias (1857): Diccionario general militar de voces antiguas y modernas, Madrid, Rivadeneyra; [11 cm; 482 pp.]

Contenidos / Macroestructura: «Prólogo», pp. v-xiv; «Explicación de abreviaturas», p. xv; «Diccionario», pp. 17-482 [3573 entradas]. Texto a una columna.

Microestructura: Las voces-guía se marcan con letra versal. Se indica la categoría gramatical y el campo de especialidad. Las unidades pluriverbales aparecen recogidas en el cuerpo de la entrada, diferenciadas del resto del texto por usar letra versalita.

Comentarios: En esta obra se incluyen «voces, modismos y frases técnicas referentes a [...] Artillería [...] Armas [...] Armaduras [...] Albeitería [...] Blasón [...] Castramentación $[\ldots]$ Condecoraciones $[\ldots]$ Esgrima $[\ldots]$ Fortificación $[\ldots]$ Gimnasia $[\ldots]$ Equitación y picadero $[\ldots]$ Ordenes militares $[\ldots]$ Táctica $[\ldots]$ Toques $[\ldots]$ Uniformes $[\ldots]$ y definiciones, en fin, de voces técnicas correspondientes a la táctica sublime, a la 
estrategia, a la logística y a la ciencia de la guerra en general. He comprendido también en este Diccionario muchas noticias [...] de los ejércitos de la antigua Roma [...] Igualmente he aceptado [...] muchas voces militares que fueron usadas por las tropas que formaron las famosas cuadrillas de la Santa Hermandad» (x-xiii).

25. D'WARTElet, Jorge (1863): Diccionario militar. Contiene las voces técnicas, términos, locuciones y modismos antiguos y modernos de los ejércitos de mar y tierra, Madrid, Imprenta de Luis Palacios; [22 cm; 767 pp.]

Contenidos / Macroestructura: «Esplicación de las abreviaturas», p. 4; «Diccionario», pp. 5-751 [7716 entradas]; «Lista de los señores suscritores», pp. 753-767. Texto a dos columnas.

Microestructura: Las voces-guía se marcan con letra versal. Se indica la categoría gramatical. Las acepciones aparecen en el cuerpo de la entrada, separadas entre sí mediante el signo $=$. Las unidades pluriverbales, diferenciadas también con letra versalita, siguen, en línea aparte, a la entrada bajo la que se subordinan. Las palabras en caracteres cursivos dentro del texto de la definición hacen referencia a voces definidas en el diccionario.

Comentarios: La mayoría de las bibliografías de los siglos XIX y XX no ofrecen el nombre completo del autor, a quien simplemente identifican por sus iniciales. Vidart, en su obra Letras y armas, es quien primero le identifica con su nombre completo y graduación.

26. AlmiRAnTe, José (1869): Diccionario militar; etimológico, histórico, tecnológico, con dos vocabularios francés y alemán, Madrid, Imprenta y Litografía del Depósito de la Guerra; [27 cm; xiv + 1218 pp.]

Contenidos / Macroestructura: «Prólogo», pp. v-xii; «Copia del informe de la extinguida Junta Consultiva de Guerra», pp. xii-xiii; «Copia del informe de la Academia Española», p. xiii; «Copia del informe de la Academia de la Historia», p. xiv; «Diccionario», pp. 1-1128 [5502 entradas]; «Vocabulario francés-español», pp. 1129-1164 [3468 entradas]; «Vocabulario alemán-español», pp. 1165-1218 [5939 entradas]. Texto a dos columnas.

Microestructura: En el «Diccionario» las voces-guía se marcan con letra versalita negrita. Las diferentes acepciones y unidades pluriverbales aparecen recogidas en el cuerpo de la entrada, diferenciadas del resto del texto por usar letra versalita. La versalita sirve también para indicar que la palabra se haya definida en su lugar correspondiente del diccionario, evitándose con el ello el uso repetitivo de abreviaturas del tipo V.e.v. (véase esta voz). Ocasionalmente se incluyen citas de textos literarios o históricos para ilustrar el significado.

En los dos vocabularios, francés-español y alemán-español, las voces-guía se marcan con letra cursiva. El equivalente o equivalentes en español del término francés aparecen en letra redonda. Las unidades pluriverbales aparecen recogidas en el cuerpo de 
la entrada, precedidas por un guión. Las remisiones entre voces-guía son muy poco frecuentes.

Comentarios: El diccionario, aunque hace supresión de «todas las voces heráldicas o del blasón [...] De los términos técnicos de hipiatría y albeitería [...] De las órdenes militares y condecoraciones extranjeras [...] De toda acción de guerra y nombre de localidad [...] De una multitud de voces, indefinidas e indefinibles por su esencia, correspondientes a ejércitos antiguos, como el egipcio, el chino o el tártaro» (vii-viii), da gran importancia a «los vocablos anticuados; porque no todos son arcaísmos, como vulgarmente se cree, y porque, si se han de regenerar nuestro lenguaje y literatura militar, sólo puede ser inspirándose en los clásicos» (ix). Por lo que respecta a los vocabularios, Almirante señala que las lenguas francesa y alemana son «as más útiles para el militar español» (xi) y que en ellos aparecen los «principales equivalentes, cuya definición y explicación se encuentran en el cuerpo del Diccionario» (xi). Esta obra fue reeditada por el Ministerio de Defensa en 1989 y 2002.

27. M. A. Diccionario militar razonado, manuscrito inédito, 4 volúmenes, copiado de varias manos, Real Academia de la Historia Ms. 2/Ms. 88, 2/Ms. 89, 2/Ms. 90, 2/Ms. 91 (olim: 2-7 ; 2-7-3/Ms. 62-2-7-3/Ms. 65). [21 cm; vol. 1 (tomo 1): iv +582 pp.; vol. 2 (tomo 2, $1^{\text {a }}$ parte): 643 pp.; vol. 3 (tomo 2, $2^{\mathrm{a}}$ parte): 537 pp.; vol. 4 (tomo 3): 640 pp.].

Contenidos / Macroestructura: Vol. 1: «Introducción», pp. i-iv; «ABANDERADOCOMISARIO DE GUERRA», pp. 1-557 [558 entradas]; «Indice de términos comprendidos», p. 559-582; Vol. 2: «COMISARIO ORDENADOR-ESTRELLAS», pp. 1-612; «Indice de términos comprendidos», p. 615-643 [412 entradas]; Vol. 3: «ESTRELLEROLUNETA», pp. 653-1168; «Indice de términos comprendidos», 1169-1190 [311 entradas]; Vol. 4: «MACHO-ZIGZAGS», pp. 1-611; «Indice de términos comprendidos», 613640 [598 entradas]. Texto a una columna.

Microestructura: Las voces-guía se marcan con letra mayúscula. Las unidades pluriverbales, en las que sólo se diferencia con letra mayúscula el primer elemento, siguen, en línea aparte, a la entrada bajo la que se subordinan. Las remisiones se indican mediante las fórmulas $V$. o Véase.

Comentarios: La obra perteneció a la biblioteca de Eduardo Fernández San Román, marqués de San Román (1818-1887). En cuanto a la posible fecha de composición del diccionario, sólo es posible determinar los límites post quem y ante quem, en concreto, las campañas napoleónicas, mencionadas en la introducción y la Bibliografía militar de España (1876) de Almirante, que cita por primera vez esta obra. En ocasiones, el texto de la definición aparece editado a lápiz, por una mano posterior a la original. En la introducción el anónimo autor comenta que los cambios producidos en la ciencia militar «exigen incontestablemente un Diccionario militar razonado que defina exactamente los términos técnicos, aclare otros, y no omita los descubrimientos e inovaciones que se han hecho hasta el presente en las diferentes ramificaciones que constituyen la ciencia de la guerra». Con relación a su composición, el autor señala que el diccionario es un «estracto, la mayor parte de obras nacionales y algunas pocas extrangeras». 
28. MATHÉ, José. Diccionario de voces militares omitidas en el de la Academia Española.

Comentarios: El Diccionario de voces militares omitidas en el de la Academia Española no aparece recogido en ninguna de las bibliografías consultadas y tampoco ha podido ser localizado en los fondos bibliográficos de ninguna biblioteca. La primera referencia a esta obra se la debemos a Ubaldo Pasabón, autor de una «Bibliografía militar» recogida en la Revista española de ambos mundos (vol. 1. 1853: 435-450) «Este es un libro utilísimo y que declara mejor que nada lo incompleto de alguna parte de nuestro Diccionario de la lengua» (449); posteriormente Luis Vidart, vuelve a mencionarla en Letras y armas (1871): «el brigadier D. José Mathé que ha dado á la luz un Diccionario de voces militares omitidas en el de la Academia Española»; y posteriormente en una conferencia pronunciada en el Ateneo de Madrid titulada «Estudios sobre la historia militar de España» en la que, entre otros asuntos, examinaba «las fuentes bibliográficas en que, en la actualidad, podía estudiarse la historia militar de España» (Revista Europea 159, 11 de marzo de 1877:316). Barado y Font (1890:594) cita también esta obra, sin ofrecer lugar de impresión ni fecha, por lo que sospechamos que nunca llegó a publicarse. El autor de este Diccionario inédito, José María Mathé y Arangua (1800$1875)$ fue brigadier de caballería, y escribió también el Diccionario y tablas de transmisión para el telégrafo militar de noche y día (1849) y la Carta telegráfica de España y Portugal (1861).

29. CAÑADA Y GISBERT, Antonio (1878): Diccionario tecnológico inglés-español: comprendiendo más de 16,000 voces y frases técnicas, correspondientes á las artes, ciencias, industria, etc. y principalmente al ejército, industria militar y material de artillería, Segovia, P. Ondero; [21 cm; 322 pp.]

Contenidos / Macroestructura: «Prólogo», p. 3; «Obras consultadas», p. 5; «Diccionario tecnológico», pp. 7-322 [16200 entradas]. Texto a dos columnas.

Microestructura: Las voces-guía se marcan con letra versal. Las unidades pluriverbales, marcadas también con letra versal, siguen, en línea aparte, a la entrada bajo la que se subordinan; en paréntesis se incluyen el resto de los componentes de la unidad pluriverbal, utilizándose el guión - para representar la voz-guía. Por lo general, las voces-guías van seguidas por su equivalente en español. En algunas ocasiones se ofrece una breve explicación del término inglés.

Comentarios: Dos son las motivaciones principales que llevan a Cañada y Gisbert a elaborar su diccionario. La primera es «llenar el vacío que se nota en nuestro idioma con la falta de un diccionario de esta clase, pues solo [existe] el escelente vocabulario de [...] D. Joaquín María Enrile, de edición agotada [...] y dedicada esclusivamente a los asuntos militares y a la artillería» (3). La segunda, coincidiendo con el establecimiento de la asignatura del inglés en la Academia de Artillería, «ser útil a mis compañeros entre quienes se va extendiendo la aficion al estudio del idioma inglés, propor- 
cionándoles los medios de verter al nuestro patrio la multitud de obras inglesas de la facultad» (3).

30. AlmiRANTE, José (1882): Diccionario militar; etimológico, histórico, tecnológico, con dos vocabularios francés y alemán, México, Tipografía de G. A. Esteva; [23 cm; vol. 1 (Abalanzarse-Chuzo): $\mathrm{xx}+701 \mathrm{pp}$.]

Contenidos / Macroestructura: Idéntica —excepto en lo referente a la paginacióna la de la edición de 1869. «[Prólogo]», pp. ii-xiv; «Copia del informe de la extinguida Junta Consultiva de Guerra», pp. xv-xvii; «Copia del informe de la Academia Española», pp. xvii-xviii; «Copia del informe de la Academia de la Historia», pp. xviii-xix; «Diccionario», pp. 1-701. Texto a dos columnas.

Microestructura: Idéntica a la de la edición de 1869.

Comentarios: El único ejemplar localizado de esta edición mexicana del diccionario de Almirante se conserva en la biblioteca de la University of Southern California. ${ }^{2}$ Desconozco si llegaron a publicarse el resto de los volúmenes que componían esta edición.

31. SALVÁ, Eusebio (1884): «Vocabulario militar y guía de la conversación español, tagalog-visaya» (vol. 2 de la Revista del ejército y armada de Filipinas). Manila: Imprenta de M. Pérez.

Comentarios: Este vocabulario aparece citado en los catálogos bibliográficos de Barrantes (1889), Pardo de Tavera (1903, ítem 2475), Vindel (1904, ítem 226) y Blake (1920, ítem 314). Sin embargo, nuestros esfuerzos para localizarlo en los fondos bibliográficos de alguna biblioteca han resultado infructuosos.

32. GILLE, Edouard (1885): Vocabulaire militaire = Militar Conversations Buch = Vocabolario militare = Vocabulario militar: destiné à se faire comprendre sans savoir la langue du pays, Paris, Renaud; [13 cm; 94 pp.; 11 hojas en blanco correspondientes a un Journal de marche. Texto paralelo francés - alemán - italiano - español]

Contenidos / Macroestructura: «Avant-Propos», p. 2; «Vorrede», p. 3; «Prefazione», p. 4; «Prólogo», p. 5; «Capítulo I: Servicio y agentes de noticias», pp. 6-8; «Capítulo II: Interrogatorio general», pp. 9-13; «Capítulo III: Requisiciones de víveres y material», pp. 14-15; «Capítulo IV: Carreteras, caminos, etc.», pp. 16-18; «Capítulo V: Accidentes de terreno», pp. 19-20; «Capítulo VI: Llanuras, valles, prados, campos y pantanos», pp. 21-22; «Capítulo VII: Ríos, arroyos, canales, lagos, estanques», pp. 2325; «Capítulo VIII: Lugares habitados, ciudades, villas, etc.», pp. 26-30; «Capítulo IX: Pérdidas en hombres, material y objetos», pp. 31-32; «Capítulo X: Enfermedades de los hombres y caballos», pp. 33-34; «Capítulo XI: Colores de banderas y uniformes»,

\footnotetext{
${ }^{2}$ Quiero manifestar mi agradecimiento a Barbara Robinson, bibliotecaria del Boeckmann Center for Iberian and Latin American Studies de la Doheny Memorial Library de la University of Southern California USC, quien muy gentilmente me facilitó información sobre esta edición.
} 
pp. 35-36; «Capítulo XII: Para salvarse ó evadir», p. 37; «Capítulo XIII: Para hacer sopa y comer», pp. 38-39; «Capítulo XIV: Para pedir trabajo», pp. 40-41; «Capítulo XV: Para alquilarse, vestirse, calzarse», pp. 42-43; "Capítulo XVI: Urbanidad y menosprecio», pp. 44-45; «Capítulo XVII: Organización del ejército», pp. 46-47; «Capítulo XVIII: Alojamiento, acantonamiento», pp. 48-49; «Capítulo XIX: Animales, reptiles, insectos incómodos», p. 50; «Capítulo XX: Alimento de los hombres, sólidos y líquidos», pp. 51-54; «Capítulo XXI: Forrages, enjaezamiento, albeitería», pp. 55-56; «Capítulo XXII: Alumbrado, provision para fuego, lavadura», p. 57; "Capítulo XXIII: Reparaciones, sastre, zapatero, etc.», p. 58; «Capítulo XXIV: Tabacos, chismes para despacho», p. 59; «Capítulo XXV: Utensilios de cocina e instrumentos», pp. 60-62; «Capítulo XXVI: Transportes por tierra y agua, arrumaje», pp. 63-64; «Capítulo XXVII: Limpieza de los hombres, diversos juegos», p. 65; «Capítulo XXVIII: Divisiones del tiempo», pp. 66-67; «Capítulo XXIX: Números», pp. 68-69; «Capítulo XXX: Delitos y penas», p. 70; «Capítulo XXXI: Respuestas diversas», p. 71; «Capítulo XXXII: Designación de las monedas», pp. 72-75; «Capítulo XXXIII: Medidas a tomar por el jefe de una tropa en país enemigo», pp. 76-84; «Capítulo XXXIV: Aviso a los habitantes», pp. 85-91; «Indice», pp. 92-94; «Journal de marche». [1395 entradas]. Texto paralelo en páginas enfrentadas a cuatro columnas, una por idioma.

Microestructura: Las voces-guía - tanto palabras sueltas como expresiones pluriverbales - se disponen en columnas paralelas en este orden: francés, alemán, italiano y español. No se incluye ninguna otra información.

Comentarios: La obra esencialmente es un diccionario de frases útiles organizado temáticamente en una serie de campos, dentro de cada uno de ellos las entradas se disponen de modo alfabético. Con este vocabulario multilingüe el autor quiso «poner a disposición de cada soldado los medios para hacerse comprender y vivir en el país enemigo» con el fin de «evitar en cuanto fuere posible las desinteligencias entre los individuos que no hablan la misma lengua» (5). Para su correcta utilización, los usuarios, «después de encontrar, sirviéndose del índice, las palabras o frases que les convengan para su comprensión no tiene más que enseñar las preguntas correspondientes en la lengua del interrogado, y el resultado obtenido será una respuesta con si o no, o un signo equivalente de cabeza» (5).

33. GARRIDO, Antonio (1885): Vocabulario militar español-alemán, Madrid, Tipografía de Diego Pacheco; [17 cm; 200 pp.]

Contenidos / Macroestructura: $1^{\text {a }}$ Parte: «Principios generales de gramática», pp. 580; $2^{\mathrm{a}}$ parte «[Phrase book»] «Capítulo I: Preliminares», pp. 81-98; $2^{\mathrm{a}}$ parte: «Capítulo II: Reconocimientos (1-Caminos, 2-Ríos, puentes, 3-Montañas, bosques, 4-Un pueblo, 5-Una aldea)», pp. 99-114; $2^{\text {a }}$ parte: «Capítulo III: Reconocimientos acerca de las fuerzas, movimientos y posiciones del enemigo (1-A un vendedor ambulante, 2-A un soldado de caballería desertor, 3-A un soldado de artillería prisionero, 4-A un guía)», pp. 115-122; $2^{\mathrm{a}}$ parte: "Capítulo IV: Acantonamientos (1-A un alcalde, 2-Alojamiento a un criado)», pp. 123-127; $3^{\mathrm{a}}$ Parte «Ejercicios de lectura y traducción», pp. 128-142; $4^{\mathrm{a}}$ Parte «Vocabulario de las palabras más usuales»; 4ª parte: «Capítulo I: 1-Ejército; 2- 
Armas; 3-Caballería, Artillería; 4-Instrucción de caballería», pp. 143-156; 4 parte: «Capítulo II: 1-Sociedad, Familia; 2-Cuerpo», pp. 157-162; 4 parte: «Capítulo III: Geografía: 1-Tierra; 2-Nombres geográficos; 3-Ciudad», pp. 163-175; 4ª parte: «Capítulo IV: Tiempo-Temperatura: 1-Tiempo; 2-Temperatura», pp. 176-179; $4^{\text {a }}$ parte: «Capítulo V: Sistema monetario de Alemania», p. 180-182; 4 ${ }^{\mathrm{a}}$ parte: «Capítulo VI: Pesos y medidas», p. 183; $4^{\mathrm{a}}$ parte: «Capítulo VII: Efectivos del ejército alemán en pié de guerra», pp. 184-185; $4^{\text {a }}$ parte: «Capítulo VIII: Marina alemana», pp. 186-192; «Indice alfabético», pp. 193-200. [659 entradas]. Texto a una columna.

Microestructura: Las voces-guía en español aparecen en la columna de la izquierda y su equivalente alemán en la de la derecha. No se incluye ninguna otra información.

Comentarios: La Parte $2^{\mathrm{a}}$ del Vocabulario militar es un diccionario de frases útiles organizado por temas. El vocabulario propiamente dicho ocupa la totalidad de la Parte $4^{\mathrm{a}}$ del libro y está organizado temáticamente en una serie de campos dentro de cada uno de ellos las entradas se disponen de modo alfabético. Hay un importante error de paginación en el Vocabulario, en el que aparecen tres secuencias diferentes: 1-152, 149-164 (153-168) y 169-200. La paginación que se ofrece en el análisis de la macroestructura corresponde a la corregida, y no a la que aparece en la obra.

\section{GARRIDO, Antonio. Guía militar español-francés-italiano-inglés-alemán.}

Comentarios: La Guía militar no aparece recogida en ninguna de las bibliografías consultadas y tampoco ha podido ser localizada en los fondos bibliográficos de ninguna biblioteca. La única referencia a esta obra aparece en la portada del Vocabulario militar español-alemán del mismo autor.

35. TREPIED, Henri (1889): Vocabulaire militaire espagnol-français: technologie militaire et maritime ancienne et moderne, Paris, Librairie Militaire de L. Baudoin et Cie.; [13 cm; 232 pp.]

Contenidos / Macroestructura: «Avant-propos», pp. 5-6; «Abréviations», p. 7; «Vocabulaire militaire espagnol-français», pp. 9-217 [5625 entradas]; «Toques/Sonneries», p. 218; «Voces de mando/Commandements militaires», pp. 219225; «Abreviaciones/Abréviations», pp. 226-227; «Poids et mesures», pp. 228-229; «Monnaies en circulation», pp. 230-232. Texto a una columna.

Microestructura: Las voces-guía en español aparecen en la columna de la izquierda y su equivalente francés en la de la derecha. Las unidades pluriverbales, y en muy contadas ocasiones las acepciones, siguen, en línea aparte, precedidas por un guión, a la entrada bajo la que se subordinan. La categoría gramatical y el campo semántico aparecen indicados en algunas entradas mediante una abreviatura en cursiva.

Comentarios: La falta de un «vocabularie spécial donnant la traduction en langue française des termes militaires espagnols» lleva al autor a componer esta obra para así «faciliter la tâche des officiers désireux d'étudier dans le texte les publications militaires de l'Espagne ancienne et moderne» (5). 
36. CAStÁÑS Y Bonelli, Atalo (1893): El traductor militar. Prontuario de francés, Madrid, Imprenta y Litografía del Depósito de la Guerra; [16 cm.; v + 119 pp.]

Contenidos / Macroestructura: «Prólogo», pp. iii-v; «Reglas generales de la pronunciación», pp. 1-12; «Reglas generales de la escritura», pp. 13-16; «Conjugaciones», pp. 18-47; «Numeración», pp. 49-51; «Palabras y locuciones usadas en el ejército y en la armada», pp. 55-80 [559 entradas]; «Connaisances nécessaires au militaire en campagne», pp. 81-93; «Divers Sujets militaires», pp. 95-106; «Histoire», pp. 107-119. Texto a una columna.

Microestructura: Las voces-guía - tanto palabras sueltas como expresiones pluriverbales - se disponen en columnas paralelas. Las voces-guía en francés aparecen en la columna de la izquierda y su equivalente español en la de la derecha. No se incluye ninguna otra información.

Comentarios: El autor, en la introducción, manifiesta la importancia del estudio de los idiomas pues «éstos son tan necesarios como las matemáticas para el fin de ingresar en una academia militar, y más aún que las matemáticas para la cultura social y científica del que aspira a ser oficial» (iii).

37. CAStÁÑS Y Bonelli, Atalo (1894): El traductor militar. Prontuario de francés, $2^{\mathrm{a}}$ ed., Madrid, Imprenta y Litografía del Depósito de la Guerra; [16 cm.; v + 119 pp.]

Contenidos / Macroestructura: idéntica a la de 1893.

Microestructura: idéntica a la de 1893.

Comentarios: Esta edición no presenta ninguna diferencia con la de 1893.

38. CAStÁñs Y Bonelli, Atalo (1895): El traductor militar. Prontuario de francés, $3^{\mathrm{a}}$ ed., Madrid, Imprenta y Litografía del Depósito de la Guerra; [16 cm.; v + 1 $\mathrm{h}+229$ pp.]

Contenidos / Macroestructura: Idéntica a la de la edición de 1893, con las siguientes diferencias: se añaden textos adicionales a las secciones «Divers sujets militaires», pp. 95-139; e «Histoire», pp. 141-183; se añaden dos nuevas secciones, «Biographies», pp. 185-228; y «Erratas importantes», p. 229. La lista de términos militares y de la armada es idéntica a la de las ediciones de 1893 y 1894. Texto a una columna.

Microestructura: Idéntica a la de 1893

Comentarios: Castáñs publicó en 1912 una cuarta edición de este Prontuario de francés en la que no se incluye la sección «Palabras y locuciones usadas en el ejército y en la armada». 
39. RuBió y Bellvé, Mariano (1895-1901): Diccionario de ciencias militares, 3 vols., Barcelona, Revista Científico Militar y Biblioteca Militar; [23 cm; vol. 1 (ACh): 986 pp.; vol. 2 (D-H): 1015 pp.; vol. 3 (I-Z): 963 pp.]

Contenidos / Macroestructura: «Prólogo», pp. v-ix; «Advertencias», p. x; «Diccionario», pp. 11-986; 5-1015; 5-963 [13113 entradas]. Texto a dos columnas.

Microestructura: Las voces-guía se marcan con letra negrita. Se indica la etimología y la correspondencia al francés, italiano, alemán e inglés. Las acepciones aparecen en el cuerpo de la entrada, en línea aparte, con la voz-guía en cursiva. Las unidades pluriverbales, diferenciadas también con letra cursiva, siguen, en línea aparte, a la entrada bajo la que se subordinan. Las palabras polisémicas se separan en entradas diferentes. Se incluyen ejemplos de uso en otras fuentes. Algunas entradas van acompañadas de ilustraciones.

Comentarios: El diccionario incluye artículos correspondientes a la historia, biografía y bibliografía militar, instrucción militar, tácticas particulares, creación y organización de los ejércitos, administración, higiene, salud militar, legislación, justicia militar, virtudes militares, armas ofensivas (portátiles, artillería, pólvoras y explosivos, etc.), armas defensivas, topografía, geografía militar, geología, fortificación, minas, trabajos diversos de campaña, medios de comunicación y transporte, marina militar, movilización de los ejércitos, concentración, estrategia, táctica general, leyes y usos de la guerra. Se incluyen también las biografías de «algunos individuos cuyos pensamientos y cuyas acciones son casi el arte de la guerra» (ix).

40. CASTÁÑS Y Bonelli, Atalo (1896): El traductor militar: Prontuario de inglés, Madrid, Imprenta y Litografía del Depósito de la Guerra; [16 cm; 220 pp.]

Contenidos / Macroestructura: «Prólogo», pp. iii-vi; «Reglas de pronunciación», pp. 1-36; «Reglas de escritura», pp. 37-39; «Conjugaciones», pp. 41-52; «Numeración», pp. 53-54; «Formación de las palabras», pp. 55-62; «Palabras y locuciones usadas en el ejército y la armada», pp. 64-106 (ejército, pp. 64-94 [1455 entradas]; armada, pp. 95-106 [603 entradas]); «Various military and naval issues», pp. 107-150; «History», pp. 151-196; «Biographies», pp. 197-212; "Adición a los vocabularios del ejército y de la armada», pp. 213-218 (ejército, pp. 213-217 [236 entradas]; armada, 218219 [88 entradas]); «Fe de erratas», p. 220

Microestructura: Las voces-guía - tanto palabras sueltas como expresiones pluriverbales, estas últimas en paréntesis) - se disponen en columnas paralelas. Las vocesguía en inglés aparecen en la columna de la izquierda y su equivalente español en la de la derecha. No se incluye ninguna otra información.

Comentarios: El autor dedica «este prontuario principalmente a la oficialidad del Ejército y de la Armada, y a los jóvenes que se preparan para el ingreso en la Escuela Naval flotante, he incluido los dos vocabularios [...]» (vi)

41. Estévanez, Nicolás (1897): Diccionario militar, París, Garnier Hermanos; [20 cm; viii + 252 pp.] 
Contenidos / Macroestructura: «Prólogo», pp. v-viii; «Diccionario militar», pp. 1228 [3113 entradas]; «Vocabulario militar español-francés-alemán», pp. 229-249. Texto a dos columnas.

Microestructura: Las voces-guía se marcan con letra negrita. Las acepciones aparecen en el cuerpo de la entrada, separadas entre sí mediante un guión. El «Vocabulario militar español-francés-alemán» incluido al final de la obra es simplemente un listado a tres columnas de los términos equivalentes en las tres lenguas. En algunas ocasiones se ofrecen varios equivalentes del término en español. Las unidades pluriverbales aparecen en línea aparte, precedidas por un guión.

Comentarios: La obra ofrece «un índice de expresiones militares, de términos empleados en la milicia española, de palabras hoy en desuso, que a veces llenan de dudas y confusiones al lector de libros militares» (v).

42. VAlencia DE Don JuAn, Conde de [Juan Bautista CROOKE Y NAVARROT] (1898): Catálogo histórico-descriptivo de la Real Armería de Madrid, Madrid, Fototipias de Hauser y Menet; [30 cm; xv $+447+4$ pp.]

Contenidos / Macroestructura: «Advertencia preliminar», p. 413; «Abreviaturas», p. 414; «Glosario», pp. 415-431 [46 entradas]. Texto a una columna.

Microestructura: Un asterisco precede a las palabras que no figuran en el Diccionario académico, y también a las que no están definidas en el sentido que se emplea en el Catálogo. Las voces-guía se marcan con letra negrita. El número que sigue a cada una de las voces-guía hace referencia a la página de la primera de las obras aportadas como ejemplo en que la voz-guía aparece citada. Equivalente en francés del término definido. Se incluyen ejemplos de uso en otras fuentes.

Comentarios: Brevísimo glosario cuya finalidad principal es «sacar del olvido muchas voces técnicas» y «definir algunas palabras cuyo sentido difiere del de las contenidas en el Diccionario de la Lengua castellana de la Real Academia Española» (413). El número que sigue a cada una de las voces-guía hace referencia a la página de la primera de las obras aportadas como ejemplo en que la voz-guía aparece citada. El asterisco precede a aquellas palabras que «no figuran en el Diccionario de la Lengua castellana por la Real Academia Española, y también a las que no están definidas en el sentido que se emplea en el Catálogo» (n. 1, p. 415). En el explicit se señala que la obra se imprimió en el Establecimiento tipográfico «Sucesores de Rivadeneyra»

43. CASTÁÑS Y BONELLI, Atalo (1900): El traductor militar. Vocabulario alemánespañol, Madrid, Imprenta y Litografía del Depósito de la Guerra; [16 cm.; pp. 197]

Contenidos / Macroestructura: «Advertencias preliminares», pp. 3-5; «Abreviaturas», p. 6; «Substantivos franco-alemanes eliminados de los vocabularios militar y naval», pp. 7-10, [183 entradas]; «Términos militares», pp. 11-160 [2430 entradas]; «Términos navales», pp. 161-190 [429 entradas]; «Apéndice: Adiciones, alteraciones, rectificaciones», pp. 191-195 [46 entradas]. Texto a una columna. 
Microestructura: Las voces-guía se marcan con letra gótica negrita. Las unidades pluriverbales, marcadas también con el mismo tipo de letra, siguen, en línea aparte precedidos de guión, a la entrada bajo la que se subordinan; para los sustantivos se ofrece en paréntesis el artículo. Las voces-guías van seguidas por su equivalente en español. Las acepciones se separan mediante $\|$. Se emplean las letras mayúsculas para distinguir los sustantivos de las demás partes de la oración. No se ofrece ningún otro tipo de información.

Comentarios: La intención del autor es «reunir en el menor volumen posible el mayor número de voces y locuciones técnicas, y presentar éstas de tal forma que el que aspire a traducir una obra militar alemana adquiera alguna idea de la organización de los ejércitos de mar y tierra de aquel poderoso imperio» (3). En esta obra se ha omitido toda la información gramatical y los textos que aparecían en obras similares del mismo autor.

44. GARCÍA PÉREZ, Antonio (1907): Vocabulario militar hispano-mogrebino, Melilla, Imprenta de El Telegrama del Rif; [22 cm; 30 pp.]

Contenidos / Macroestructura: «[Dedicatoria]», p. 5; «Vocabulario», pp. 7-30 [406 entradas]. Texto a una columna.

Microestructura: Las voces-guía - tanto palabras sueltas como expresiones pluriverbales - se disponen en columnas paralelas. Las voces-guía en español aparecen en la columna de la izquierda y su equivalente árabe, con su correspondiente transliteración, en la de la derecha. Se indican entre paréntesis los plurales. No se incluye ninguna otra información.

Comentarios: El autor, capitán de infantería, dedica la obra a D. Ramón Echagüe y Mendez-Vigo, Conde del Serrallo y general de división. El vocabulario carece de materia introductoria.

45. GIL JUSTE, Germán (1907): Vocabulario militar: español-inglés é inglésespañol, Madrid, Establecimiento tipográfico El Trabajo; [16 cm.; 154 pp.]

Contenidos / Macroestructura: «[Prólogo]», pp. 5-6; «Abreviaturas», p. 7; «Español-Inglés», pp. 9-84 [1245 entradas]; «Inglés-Español», pp. 85-154. [1149 entradas]. Texto a una columna.

Microestructura: Las voces-guía en español (o inglés) aparecen en la columna de la izquierda y su equivalente inglés (o español) en la de la derecha. Las unidades pluriverbales y las acepciones siguen, en línea aparte, precedidas por un guión, a la entrada bajo la que se subordinan. Se separan mediante \| las acepciones en la columna correspondiente a los equivalentes. El campo semántico, y en el vocabulario inglés-español, la categoría gramatical, aparecen indicadas en algunas entradas mediante una abreviatura.

Comentarios: El autor, comandante de infantería, prepara el vocabulario para «satisfacer una necesidad sentida por todos aquellos de nuestros compañeros que estudian 
el inglés y desean ponerse pronto en condiciones de sostener, en dicha lengua, un conversación profesional» (5). En la obra se recogen, «además de todos los términos técnicos y frases militares que hemos podido recoger, los términos topográficos más comunes, los referentes á la anatomía externa del caballo, cuando éstos difieren, en inglés, de los empleados en la anatomía humana, y los verbos y locuciones más generalmente usados en el lenguaje militar» (5).

46. Santa Olalla, Fausto (1908): Compendio de gramática árabe vulgar y Vocabulario hispano-árabe militar, Tánger, Establecimiento Tipográfico de S. Benaioun; [22 cm; 135 pp.]

Contenidos / Macroestructura: «Prólogo», pp. 3-4; «Compendio de la gramática árabe vulgar», pp. 5-58; «Apéndice», pp. i-xxii; «Vocabulario hispano-árabe militar», pp. 1-71 [2154 entradas]; «[Apéndice]», pp. 72-80: «Voces de mando», pp. 72-74; «Manejo del arma», pp. 74-75; «Voces generales», pp. 75-77; «El fusil», pp. 77-78; «Vestuario», pp. 78-80, [221 entradas] ; «Reglamento para los cuerpos de policía», pp. 81-135. El dígrafo $\mathrm{CH}$ no tiene consideración de letra independiente. Texto a una columna.

Microestructura: Las entradas del Vocabulario aparecen divididas en tres columnas. En la de la izquierda se sitúan las voces-guía en español; en la central aparece la transliteración de las palabras árabes; en la de la derecha, el equivalente árabe. Para cada una de las frases en árabe se ofrece su traducción literal al castellano. Las unidades pluriverbales y las acepciones siguen, en línea aparte, precedidas por », a la entrada bajo la que se subordinan. Se indica mediante abreviatura la categoría gramatical de un número reducido de entradas.

En el Apéndice las entradas presentan la misma disposición, aunque no aparecen ordenadas alfabéticamente.

Comentarios: El autor, comandante de infantería y jefe instructor de la policía militar de Marruecos, reúne en el Compendio los materiales recogidos durante su estancia en Río de Oro con la intención de trazar un sistema de aprendizaje del árabe vulgar que «determina un desarrollo progresivo y eficaz para difundir con presteza todos los elementos que entran en la composición del lenguaje, esencialmente militar en sus ejemplos» (4). En el Vocabulario se recogen «todas las palabras de uso frecuente en los cuarteles, parques, talleres, oficinas y hospitales, en los servicios de guarnición y de campaña y por consiguiente son de tan común aplicación para los que pertenecen a las armas de combate como para los que prestan servicio en cuerpos asimilados de tierra y mar» (4). El autor explica en el Compendio las normas de empleadas en la transliteración de las palabras árabes.

47. LeguINA, Enrique de (1912): Glosario de voces de armería, Madrid, Librería de Felipe Rodríguez; [26 cm; 884 pp.]

Contenidos / Macroestructura: «Advertencia», pp. 5-9; «Inventarios, glosarios y diccionarios consultados», pp. 11-16; «[Glosario]», pp. 17-882 [3332 entradas]; «Erratas importantes», p. 883. Texto a una columna. 
Microestructura: Las voces-guía se marcan con letra negrita y van seguidas por la definición o una remisión. En algunos casos se ofrece fragmento de texto extraído de la fuente que sirve de autoridad. Las remisiones se indican mediante la fórmula. V.

Comentarios: Leguina pretende con su glosario ayudar a todos cuantos «han experimentado, alguna vez, la contrariedad que produce el hallar un párrafo interesante y no acertar a dárse cuenta exacta de lo que expresa, á causa de desconocer el significado de voces anticuadas [...] cuyo sentido no es fácil de determinar, por referirse a olvidados hábitos ó corresponder á ciertas industrias artísticas que han sufrido honda y radical transformación» (5). El glosario «no sólo voces de armería, sino algunas otras que tienen relación con lo que constituye el objeto principal de este estudio, ya por significar telas y trajes usados con las armaduras, ya variedades de caballos en aquellos tiempos en que la jineta era un arte, y algunos términos de esgrima usados cuando la destreza de las armas alcanzaba la categoría de verdadera Sciencia» (7-8). En aquellas ocasiones en las que el término no aparece definido en ningún vocabulario el autor se limita a «expresar una interpretación deducida de textos autorizados» (8), consignando el término sin definir en aquellos casos que no consiguió «averiguar lo que la palabra quiere expresar» (8).

\section{REFERENCIAS BIBLIOGRÁFICAS}

Aguilar Piñal, Francisco (1981- ): Bibliografia de autores españoles del siglo XVIII, Madrid, CSIC.

AhumadA, Ignacio (2000): «Diccionarios de especialidad en los siglos XVIII, XIX y XX», en I. Ahumada, ed., Cinco siglos de lexicografia del español. IV Seminario de Lexicografía Hispánica (Jaén, 17-19 de noviembre de 1999), Jaén, Universidad de Jaén, pp. 79-102.

Almirante, José (1876): Bibliografía militar de España, Madrid, Imprenta y fundición de Manuel Tello.

(1989): Diccionario militar, Madrid, Ministerio de Defensa. (2002): Diccionario militar, Madrid, Ministerio de Defensa.

ANÓNIMO. (1877): «Cátedra del Señor Vidart. Estudios sobre la historia militar de España», Revista Europea, 159, pp. 316-319.

Aubert de la Chesnaye-Desbois, François-Alexandre (1742): Dictionnaire militaire, ou, Recueil alphabetique de tous les termes propres à l'art de la guerre: on y a joint 
l'explicatin des travaux qui servent à l'attaque, \& à la défense des places, \& des détails historiques sur l'origine \& la nature des différentes especes, tant d'officesmilitaires, anciens \& modernes, que des armes qui ont été en usage dans les différens tems de la monarchie, París, Chez Gissey \& Chez Bordelet.

AZORÍN FERnÁNDEZ, Dolores (1996): «La lexicografía española en el siglo XIX. Desarrollos y tendencias», en E. Serra Alegra et al., eds.: Panorama de la Investigació Lingüística a l'Estat Espanyol. Actes del I Congrés de Lingüística General, València, 15, 16 i 17 de febrer de 1994, Valencia, Universitat de València, 2, pp. 48-54.

BAQUero MESA, Rosario (1992): «Notas en contribución a la historia de la lexicografía española monolingüe del siglo XIX», en Euralex '90 Proceedings. Actas del IV Congreso Internacional. IV International Congress [Benalmádena (Málaga), 28 agosto-1 septiembre 1990], Barcelona, Biblograf, pp. 455-461.

BARADO Y FONT, Francisco (1890): Literatura militar española, Barcelona, Tipografía La Academia.

BARRANTES, Vicente (1889): El Teatro Tagalo, Madrid, Tipografía de Manuel G. Hernández.

BIBLIOTECA NACIONAL (http://catalogo.bne.es/uhtbin/webcat).

BIBLIOTHEQUE NATIONALE (http://catalogue.bnf.fr).

BlaKE, Frank Ringgold (1920): «A Bibliography of the Philippine Languages. Part I», Journal of the American Oriental Society, 40, pp. 25-70.

BRITISH LIBRARY (http://catalogue.bl.uk).

CAPEL SÁEZ, Horacio et al. (1983): Los ingenieros militares en España. Siglo XVIII. Repertorio biográfico e inventario de su labor científica y espacial, Barcelona, Universitat de Barcelona.

CATÁLOGO COLECTIVO DE REBIUN (http://rebiun.absysnet.com/cgi-bin/rebiun).

CATÁLOGO COLECTIVO DEL PATRIMONIO BIBLIOGRÁFICO ESPAÑOL (http://www.mcu.es/bibliotecas/MC/CCPB/index.html).

FABBrI, Maurizio (1979): A Bibliography of Hispanic Dictionaries: Catalan, Galician, Spanish, Spanish in Latin America and the Philippines, Imola, Galeati. (2002): A Bibliography of Hispanic Dictionaries: Basque, Catalan, Galician, Spanish, Spanish in Latin America and the Philippines. Supl. 1, Rimini, Panozzo.

GAGO-Jover, Francisco (2008): «Glosarios y diccionarios militares del siglo XIX», en $A c$ tas del II Congreso Internacional de Lexicografia Hispánica: El diccionario como 
puente entre las lenguas y culturas del mundo, Alicante, Taller Digital-Fundación Biblioteca Virtual Miguel de Cervantes, pp. 670-677.

y Fernando TeJedo Herrero (2007): Diccionario militar de Raimundo Sanz: Edición y estudio, Zaragoza, Institución Fernando el Católico.

GARCÍA DE LA HUERTA, Vicente (1760): Bibliotheca militar española, Madrid, Antonio Pérez de Soto.

GARCÍA Platero, Juan Manuel (2003): «La lexicografía no académica en los siglos XVIII y XIX», en A. M. Medina Guerra, coord., Lexicografía española, Barcelona, Ariel, pp. 263-280.

Geoghegan, Abel Rodolfo (1965): Obras de referencia de América Latina: Repertorio selectivo y anotado de enciclopedias, diccionarios, bibliografias, repertorios bibliográficos, catálogos, guías, anuarios, índices, etc., Buenos Aires, Imprenta Crisol.

GIL FERNÁNDEZ, Luis (1984): «Una labor de equipo: La Editio Matritensis de Juan Ginés de Sepúlveda», en Estudios de Humanismo y tradición clásica, Madrid, Universidad Complutense, pp. 127-162.

GOOGLE BOOKS (http://books.google.com/books).

HARDIN, Craig (1971 $\left.{ }^{4}\right)$ : A Bibliography of Encyclopedias and Dictionaries Dealing with Military, Naval, and Maritime Affairs, 1577-1971, Houston, Dept. of History, Rice University.

HidAlgO, Dionisio (1862-1881): Diccionario general de bibliografía española, Madrid, Imprenta de las Escuelas Pías.

Keralio, Louis Félix Guinement de (1784-1797): Art militaire, París-Lieja, PanckouckePlomteux.

Laplana, J. de R. (1851): Retrato de José María Mathe y Arangua, Madrid, Oficinas y Establecimiento Tipográfico del Semanario Pintoresco y de La Ilustración.

LIBRARY OF CONGRESS (http://catalog.loc.gov/).

López de Ayala, María José y Matilde Conde Salazar. (1994): «Diccionario militar para la traducción del De rebus gestis Caroli $V$ de J. G. de Sepúlveda», Epos: Revista de filología, 10, pp. 33-50.

LosADA, Ángel (1949): Juan Ginés de Sepúlveda a través de su epistolario y nuevos documentos, Madrid, CSIC-Instituto Francisco de Vitoria.

MATHÉ, José María (1849): Diccionario y tablas de transmisión para el telégrafo militar de noche y dia, Barcelona, Imprenta de Antonio Brusi. 
et al. (1861): Carta telegráfica de España y Portugal, París, Librairie Militaire de J. Dumaine.

NIEDEREHE, Hans-Joseph (1994): Bibliografia cronológica de la lingüística, la gramática y la lexicografía del español (BICRES I), desde los comienzos hasta el año 1600, Amsterdam, J. Benjamins.

(1999): Bibliografía cronológica de la lingüistica, la gramática y la lexicografía del español (BICRES II), desde el año 1601 hasta el año 1700, Amsterdam, J. Benjamins.

(2005): Bibliografía cronológica de la lingüistica, la gramática y la lexicografía del español (BICRES III), desde el año 1701 hasta el año 1800, Amsterdam, J. Benjamins.

PALAU Y DULCET, Antonio (1948-1977²): Manual del librero hispanoamericano: bibliografía general española e hispano-americana desde la invención de la imprenta hasta nuestros tiempos, Barcelona, Librería Palau.

PALFREY, Thomas R. et al. $\left(1971^{8}\right)$ : A Bibliographical Guide to the Romance Languages and Literatures, Evanston, Chandler.

PARDo DE TAVERA, Trinidad Hermenegildo (1903): Biblioteca Filipina, Washington, DC, Library of Congress.

PASABÓN, Ubaldo (1853): «Bibliografía militar», Revista española de ambos mundos, 1, pp. 435-450.

PezzI, Rafael (1905): Catálogo de la biblioteca del Centro del Ejército y de la Armada, Madrid, Imprenta de los hijos de M. G. Hernández.

Porto DAPENA, José-Álvaro (2002): Manual de técnica lexicográfica, Madrid, Arco/Libros.

San Vicente Santiago, Félix (1995): Bibliografia de la Lexicografía Española del Siglo XVIII, Padova, Piovan.

(1996): «Lexicografía y catalogación de nuevos saberes en España durante el Siglo XVIII», en J. Álvarez Barrientos y J. Checa Beltrán, eds., El siglo que llaman ilustrado. Homenaje a Francisco Aguilar Piñal, Madrid, CSIC, pp. 781-794.

SeCo y Shelly, Manuel (1877): La pluma y la espada. Apuntes para un diccionario de militares escritores, Madrid, Imprenta de J. J. de las Heras.

SERÍs, Homero (1964): Bibliografia de la lingüistica española, Bogotá, Instituto Caro y Cuervo. 
VIDART, Luis (18712): Letras y armas, Madrid, Imprenta de El Correo Militar. (1888): Vida y escritos del teniente coronel capitán de artillería Don Vicente de los Ríos, Madrid, Imprenta del Cuerpo de Artillería.

Vindel Álvarez, Pedro (1904): Catálogo sistemático e ilustrado de la biblioteca filipina, Madrid.

WORLDCAT (http://www.worldcat.org). 